\title{
WHO MPOWER tobacco control scores in the Eastern Mediterranean countries based on the 2011 report
}

\author{
Gh. Heydari, ${ }^{1,2}$ F. Talischi, ${ }^{2}$ H. Algouhmani, ${ }^{3}$ H.A. Lando ${ }^{4}$ and A. Ebn Ahmady ${ }^{5}$
}

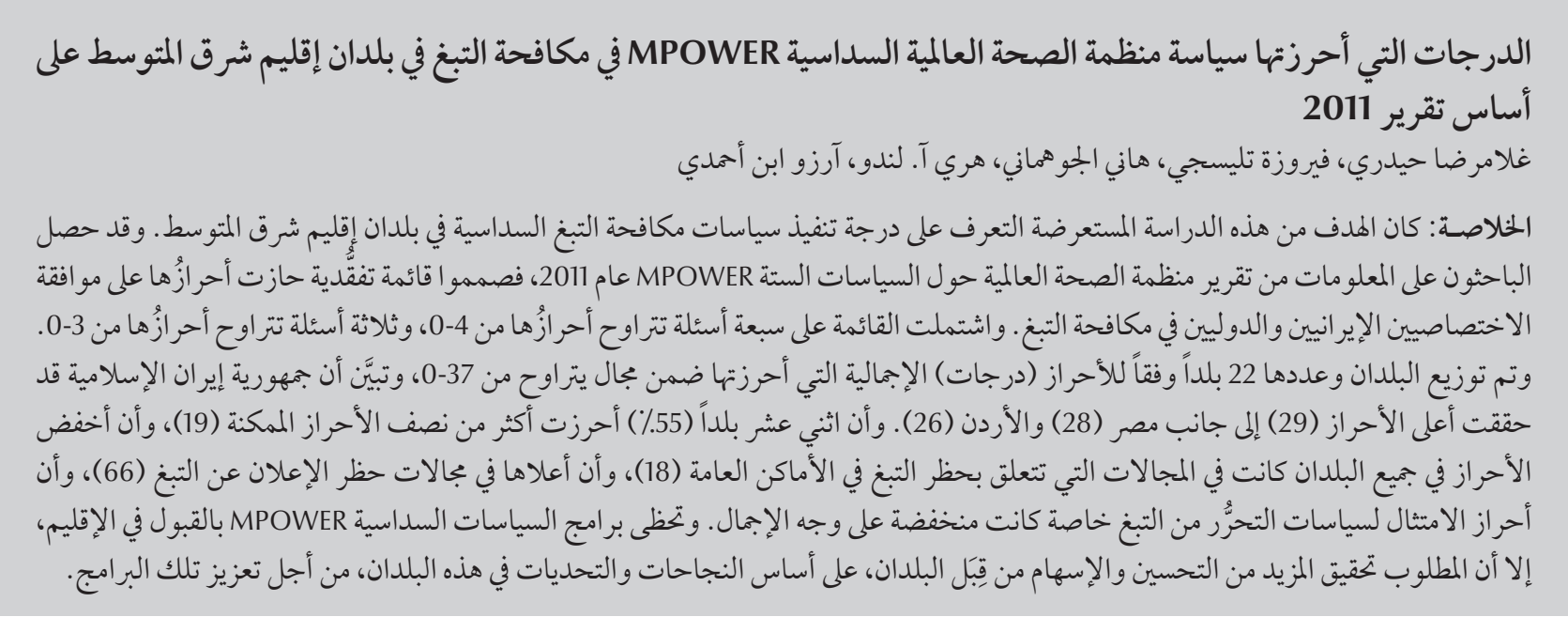

ABSTRACT The aim of this cross-sectional study was to quantify the implementation of MPOWER tobacco control policies among Eastern Mediterranean Region countries. Information was obtained from the 2011 WHO MPOWER report. A checklist was designed and its scoring was agreed by Iranian and international tobacco control specialists. Seven questions were scored from 0-4 and 3 from 0-3. The 22 countries were ranked by their total score on a scale of 0 to 37. The highest scores were achieved by the Islamic Republic of Iran, Egypt and Jordan 29, 28 and 26 respectively. Twelve of the countries (55\%) scored more than half of the possible score (19). The lowest and highest scores for all countries summed were on sections related to banning smoking in public places (18) and tobacco advertising bans (66) respectively. Compliance with smoke-free policies was especially low. MPOWER programmes are accepted in the Region but there is considerable room for improvement. Input from countries based on their successes and challenges is needed to strengthen the programmes.

Scores MPOWER OMS pour la lutte antitabac dans les pays de la Méditerranée orientale issus du rapport 2011

RÉSUMÉ La présente étude transversale visait à évaluer la mise en œuvre des politiques de lutte antitabac MPOWER dans les pays de la Région de la Méditerranée orientale. Les informations ont été obtenues à partir du rapport MPOWER de 2011 de l'Organisation mondiale de la Santé. Une liste de vérification a été élaborée et sa notation a été décidée en accord avec des spécialistes de la lutte antitabac internationaux et iraniens. Sept questions ont été notées sur une échelle allant de 0 à 4 et trois questions sur une échelle de 0 à 3. Les 22 pays ont été classés en fonction de leur score total sur une échelle allant de 0 à 37. Les scores les plus élevés ont été obtenus par la République islamique d'Iran (29), I'Égypte (28) et la Jordanie (26). Douze pays (55\%) ont obtenu des scores supérieurs à la moitié du score maximal (19). Les scores les plus faibles et les plus élevés cumulés pour l'ensemble des pays concernaient I'interdiction de fumer dans les lieux publics (18) et l'interdiction de la publicité en faveur du tabac (66). Le respect des politiques d'interdiction du tabagisme était particulièrement faible. Le programme MPOWER est accepté dans la Région mais beaucoup d'améliorations peuvent encore être apportées. Il est souhaitable que les pays mettent en commun leurs succès et leurs difficultés en la matière pour renforcer les programmes.

${ }^{1}$ Tobacco Prevention and Control Research Center; ${ }^{2}$ National Research Institute of Tuberculosis and Lung Diseases, Shahid Beheshti University of Medical Sciences, Tehran, Islamic Republic of Iran . ${ }^{3}$ Framework Convention Alliance (FCA), Tehran, Islamic Republic of Iran. ${ }^{4}$ Division of Epidemiology and Community Health, School of Public Health, University of Minnesota, Minneapolis, United States of America. ${ }^{5}$ Community Oral Health Department, School of Dentistry, Shahid Beheshti University of Medical Sciences, Tehran, Islamic Republic of Iran (Correspondence to A. EbnAhmady:a.ebnahmady@sbmu.ac.ir; aebnahmady@yahoo.com).

Received: 21/11/11; accepted: 21/02/12 


\section{Introduction}

There is ample and indisputable evidence of the dangers of tobacco smoking [1-10]. Tobacco use kills half of those who smoke [2] and it decreases life expectancy on average by 15 years [2-4]. Worldwide 5 million people currently die from tobacco every year [1]. Without effective tobacco control measures, it is estimated that by the year 2030 the annual global death toll will reach 8 million $[1,5]$. In the absence of effective tobacco control measures, consumption is likely to increase in many countries [11]. Indeed, developing countries are facing an increased prevalence of tobacco consumption, but unlike developed countries have not yet faced the full burden of resulting illness and morbidity $[5,7]$. In our Region, according to the latest data, smoking prevalence is still increasing or has plateaued [8].

To counter the global tobacco epidemic, the World Health Organization (WHO) developed the WHO Framework Convention on Tobacco Control (WHO FCTC) to provide new legal dimensions for international health cooperation. As of 12 February 2012 the treaty has been ratified by 174 parties who wish to decrease the supply and demand of tobacco [12]. In this regard, WHO introduced a package of measures under the acronym of MPOWER with the aim of reducing tobacco consumption and prevalence [13]. This package focuses on 6 proven policies for tobacco control to reduce consumption which include: monitoring tobacco use and prevention policies, protecting people from tobacco smoke, offering help to quit tobacco use, warning about the dangers of tobacco, enforcing bans on tobacco advertising, promotion and sponsorship, and raising taxes on tobacco.

Several scoring systems have been developed in different countries to evaluate anti-tobacco activities and their implementation. Gilpin and colleagues developed an index for the United States (US) state tobacco control outcomes based on cigarette prices and workplace and home smoking bans [14]. Chriqui and colleagues [15] applied a rating system to state indoor air laws in the US, and the American Lung Association measures tobacco control activities at the state level based on spending, smoke-free air laws, cigarette excise tax and youth access laws [16]. Jossens and Raw developed a tobacco control scale according to a World Bank list of effective tobacco control interventions and applied it to 30 European countries [17]. Their initial results showed countries ranked by their score and discussed the merits and limitations of the scale.

No such study has been done in the Eastern Mediterranean Region. Thus the aim of our study was to compare MPOWER Programnes among the countries of the WHO Eastern Mediterranean Region to highlight what has been achieved and what still needs to be addressed by the countries to strengthen these programmes.

\section{Methods}

This was a cross-sectional study with collection of information from the WHO programme of tobacco prevention in the EMR countries found on pages $1-140,9-128,7-116,3-102$ from the MPOWER 2011 report [18].

A checklist of indicators was initially designed by Iranian and international tobacco control specialists and its cutoffs were set according to the scoring key sections of the MPOWER 2011 report. In order to score the checklist and create the scale, we convened a panel of experts [including 3 tobacco control experts, 1 public health specialists and 1 epidemiologist from the Tobacco Prevention and Control Research Center, National Research Institute of Tuberculosis and Lung Disease (NRITLD), Tehran] to determine the allocation of points to the scale. Thus, 7 questions were scored from $0-4$ and 3 from $0-3$, giving a maximum possible score of 37 .

Five raters (medical doctors from the Tobacco Prevention and Control Research Center, NRITLD) were selected by the principle investigators. They went through a lengthy training process conducted by 1 experienced tobacco control expert (Head, Tobacco Prevention and Control Research Center) and 1 experienced rater (medical doctor from the Tobacco Prevention and Control Research Center). The training involved reading about the tobacco control policies that were the focus of the study and the scoring section of the MPOWER 2011 report. After the training and considered ready by the project coordinator, the raters carried out the subject review and their first scoring report was observed by the experienced rater. The reports were observed again by the project coordinator, who selected 2 final raters and determined when they were ready to work alone.

In order to achieve and maintain calibration between the 2 raters, the project coordinator gave them with 1 subject to report independently. Statistical analysis of the reliability of their ratings was used to maintain acceptable levels of reliability for the study. A correlation coefficient of 0.80 was calculated between these 2 raters. Data entry was done independently by the first selected rater and was checked by the second. At least 2 of these reports were selected randomly and observed in order to monitor their rating against those made by the original coordinator, the tobacco control expert and the experienced rater.

The scores were summed and the rankings were computed. The checklist, with its scoring and scale, is shown in Table 1.

\section{Results}

Weuncovered large differences in scores across EMR countries. The results are shown in Table 2. Countries are ranked 


\begin{tabular}{|c|c|}
\hline Indicator & Point scoring \\
\hline Adult daily smoking prevalence & (4) \\
\hline Estimates not available & 0 \\
\hline$\geq 30 \%$ or more & 1 \\
\hline $20 \%-29 \%$ & 2 \\
\hline $15 \%-19 \%$ & 3 \\
\hline$<15 \%$ & 4 \\
\hline Monitoring: prevalence data & (3) \\
\hline No known data or no recent data or data that is neither recent nor representative & 0 \\
\hline Recent and representative data for either adults or youth & 1 \\
\hline Recent and representative data for both adults and youth & 2 \\
\hline Recent, representative and periodic data for both adults and youth & 3 \\
\hline Smoke-free policies & (4) \\
\hline Data not reported & 0 \\
\hline Up to 2 public places completely smoke-free & 1 \\
\hline 3-5 public places completely smoke-free & 2 \\
\hline 6-7 public places completely smoke-free & 3 \\
\hline All public places completely smoke-free & 4 \\
\hline Cessation programmes & (4) \\
\hline Data not reported & 0 \\
\hline None & 1 \\
\hline NRT and/or some cessation services (neither cost-covered) & 2 \\
\hline NRT and/or some cessation services (at least 1 cost-covered) & 3 \\
\hline National quit line, and both NRT and some cessation services cost-covered & 4 \\
\hline Health warning on cigarette packages & (4) \\
\hline Data not reported & 0 \\
\hline No warnings or small warnings & 1 \\
\hline Medium-sized warnings missing some appropriate characteristics & 2 \\
\hline Medium-sized warnings with all appropriate characteristics & 3 \\
\hline Large warnings with all appropriate characteristics & 4 \\
\hline Anti-tobacco mass media campaigns & (4) \\
\hline Data not reported & 0 \\
\hline No campaign conducted between January 2009 and August 2010 & 1 \\
\hline Campaign conducted with 1-4 appropriate characteristics & 2 \\
\hline Campaign conducted with 5-6 appropriate characteristics & 3 \\
\hline Campaign conducted with all appropriate characteristics & 4 \\
\hline Advertising bans & (4) \\
\hline Data not reported & 0 \\
\hline Complete absence of ban in print media & 1 \\
\hline Ban on national television, radio and print media only & 2 \\
\hline Ban on national and some international television, radio and print media & 3 \\
\hline Ban on all forms of direct and indirect advertising & 4 \\
\hline Taxation & (4) \\
\hline Data not reported & 0 \\
\hline$\leq 25 \%$ of retail price is tax & 1 \\
\hline $26 \%-50 \%$ of retail price is tax & 2 \\
\hline $51 \%-75 \%$ of retail price is tax & 3 \\
\hline $75 \%$ of retail price is tax & 4 \\
\hline Compliance with bans on advertising & (3) \\
\hline Complete compliance (8/10 to $10 / 10)$ & 3 \\
\hline Moderate compliance (3/10 to $7 / 10)$ & 2 \\
\hline Minimal compliance (0/10 to $2 / 10)$ & 1 \\
\hline Not reported & 0 \\
\hline Compliance with smoke-free policy & (3) \\
\hline Complete compliance (8/10 to $10 / 10)$ & 3 \\
\hline Moderate compliance $(3 / 10$ to $7 / 10)$ & 2 \\
\hline Minimal compliance (0/10 to $2 / 10)$ & 1 \\
\hline Not reported & 0 \\
\hline Total score & 37 \\
\hline
\end{tabular}




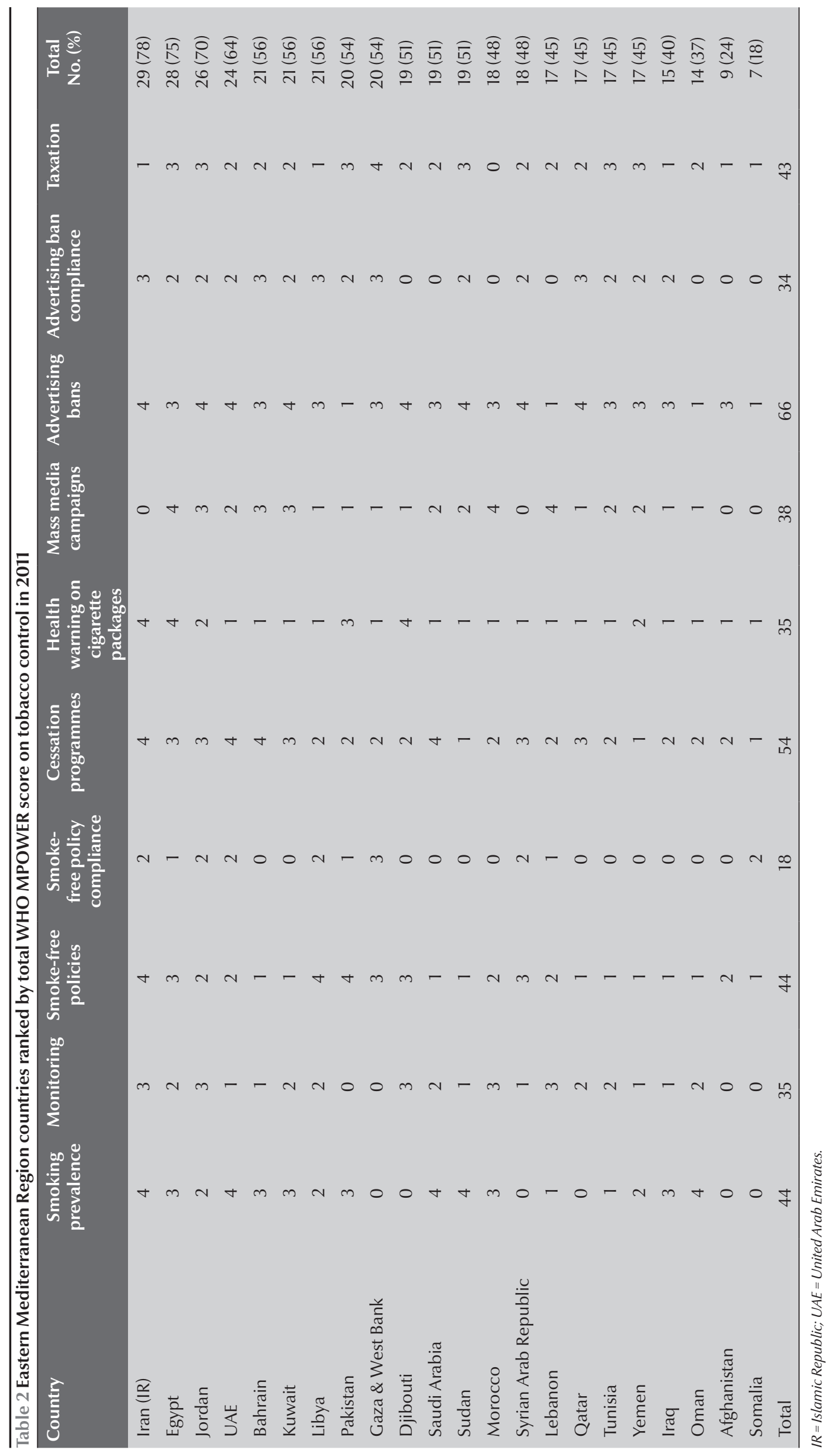


by total score, and the score obtained for each indictor for each activity. The highest total scores were achieved by the Islamic Republic of Iran, Egypt and Jordan (29, 28, 26 respectively). Twelve countries (55\%) achieved more than half of the maximum score (19). Despite its overall high score, the Islamic Republic of Iran did not score well on mass media campaigns and tobacco taxation. The Syrian Arab Republic, Afghanistan and Somali scored the lowest on mass media campaigns with no campaigns conducted between January 2009 and August 2010, while Morocco, Egypt and Lebanon scored highest. More than $50 \%$ of the countries (12) did not report on compliance on smoke-free policy; whereas Gaza reported complete compliance with smoke-free policy. All 22 countries reported having at least minimal restrictions on advertising. There was a considerable range of scores on most questions. The indictor with the lowest combined score for all countries was compliance with smoke-free policy (18) while the indicator with the highest combined score for all countries was tobacco advertising bans (66). Only 12 countries scored above $50 \%$, and the countries could be roughly divided into 3 groups: those with $\geq 70$ ( 3 countries), those with 37-64 (16 countries) and those with $\leq 24$ ( 3 countries).

\section{Discussion}

This paper reports on the differences in implementing of 6 tobacco control policies in EMR countries based on the MPOWER 2011 report. It is the first study from MPOWER in the Region so there are no published comparison data for the Region. However, Heydari and colleagues [19] examined tobacco control scales in 2009 that showed a general view for tobacco control programme in countries which had the same finding.

It is noted that many countries scored the same and there was little difference in scores for several countries. For example, Bahrain, Kuwait and Lebanon scored 21, Pakistan and Gaza 20 and Djibouti, Serbia and Sudan scored 19.

In the studies of Gilpin and colleagues [14] and Chriqui and colleagues [15] their scoring systems compared tobacco control policies within the same legal system, so measurement of enforcement and comparisons were easier. In a study by Joossens and Raw [17], which used a different but similar methodology to our study, it was shown that only $50 \%$ of European countries scored more than $50 \%$, which is similar to what we found for the EMR countries (55\% or 12 countries scored higher than $50 \%)$. Yet, in the previous study, only $14 \%$ or 3 countries achieved this score [19]. It can be concluded that these countries (Islamic Republic of Iran, Jordan and Egypt) are more active in tobacco control programmes, but that there is still room for improvement.

The results of this study show that the Islamic Republic of Iran, despite ranking first, had low scores on mass media campaigning and taxation. This information can be helpful for health officials who might want to strengthen the tobacco control programmes in illustrating the measures that could be targeted. Similar suggestions for improvement can be made in other countries based on the results of this study.

Egypt, Jordan, Pakistan, Sudan and Yemen scored well in taxation and increased cigarette prices. West Bank and the Gaza scored the highest in these policies.

Our study found that many countries either have not banned smoking in public places or are weak in this regard (12 countries scored 0 and 3 countries scored 1 out of a total of 3$)$. The average country score for this indicator was 18 , which was the lowest for the categories assessed. On the other hand, bans on tobacco advertisements had a combined score of 66 and was the most popular legal effort undertaken.

The current data were gathered from the 2011 MPOWER report. We acknowledge that the developed scale depends critically on these data and this is the first time such a scale has been applied to EMR countries. As these data were collected from the WHO report and were clear and easy to understand, we see no serious limitation to the applicability of this scale.

In conclusion, tobacco control measures according to MPOWER are generally well accepted, permit comparisons across EMR countries and provide preliminary results using a systematic scoring system. The current findings indicate that although progress has been made, there is significant room for improvement and regional countries should take steps to build on their successes and should continue to work on strengthening their weak points.

\section{References}

1. Mathers CD, Loncar D. Projections of global mortality and burden of disease from 2002 to 2030. PLoS Medicine, 2006, 3:e442.

2. Peto R et al. Mortality from smoking worldwide. British Medical Bulletin, 1996, 52:12-21.

3. US Department of Health and Human Services. The health consequences of smoking: a report of the Surgeon General. Atlanta, GA, US Department of Health and Human Services, Centers for Disease Control and Prevention, National Center for Chronic Disease Prevention and Health, Promotion, Office on Smoking and Health, 2004.

4. Peto R et al. Mortality from tobacco in developed countries: indirect estimation from national vital statistics. Lancet, 1992, 339:1268-1278.

5. Murray CJL, Lopez AD. Alternative projections of mortality and disability by cause 1990-2020: Global Burden of Disease Study. Lancet, 1997, 349:1498-1504. 
6. Levine R, Kinder M. Millions saved: proven success in global health. Washington DC, Routledge, 2006.

7. Peto R, Lopez AD. Future worldwide health effects of current smoking patterns. In: Koop CE, Pearson CE, Schwarz MR, eds. Critical issues in global health. San Francisco, Wiley (JosseyBass), 2001:154-161.

8. Erikson M, Mackay J, Ross H. The tobacco atlas, 4th ed. Atlanta, American Cancer Society and New York, World Lung Foundation, 2012.

9. Benowitz NL. Pharmacology of nicotine: addiction and therapeutics. Annual Review of Pharmacology and Toxicology, 1996, 36:597-613.

10. Battling big tobacco: Mike Wallace talks to the highest-ranking tobacco whistleblower. CBS News, 2005 (www.cbsnews. com/2100-500164-162-666867.html, accessed 5 December 2007 ).

11. Hendricks PS et al. The early time course of smoking withdrawal effects. Psychopharmacology, 2006, 187:385-396.

12. Guindon GE, Boisclair D. Past, current and future trends in tobacco use. Washington DC, World Bank, 2003
13. WHO Report on the Global Tobacco Epidemic, 2008: The MPOWER package. Geneva, World Health Organization, 2008.

14. Gilpin EA et al. Index for US state tobacco control initial outcomes. American Journal of Epidemiology, 2000, 152(8):727738.

15. Chriqui JF et al. Application of a rating system to state clean indoor air laws (USA). Tobacco Control, 2002, 11(1):26-34.

16. State of tobacco control, 2004 report. New York, Washington DC, American Lung Association, 2005.

17. Joossens L, Raw M. The Tobacco Control Scale: a new scale to measure country activity. Tobacco Control, 2006, 15:247-253.

18. WHO report on the Global Tobacco Epidemic, 2011: warning about the dangers of tobacco. Geneva, World Health Organization, 2011.

19. Heydari $\mathrm{G}$ et al. Comparison of tobacco control policies in the Eastern Mediterranean Countries based on tobacco control scale scores. Eastern Mediterranean Health Journal, 2012, 18:804-810.

\section{Note from the Tobacco Free Initiative programme}

This article is based on the information in the WHO report on the global tobacco epidemic, 2011, which is also founded on legislations issued in 2010. Since then, many legislations have been adopted at the national level, which makes the profile of tobacco control measures different from that reflected in the article. However, the article may serve well as a baseline for data of 2011. In addition, due to new evidence on second-hand smoke mortality, the total global deaths attributed to tobacco use are now reaching 6 million, which is significantly different from the number included in the article which is based on old estimates. 